\title{
Techniques Used in the Failure Analysis of Railcar Bolsters
}

\author{
D.A. Turnquist, F.E. Schmidt, PhD., M.J. Danko
}

Engineering Systems Inc., Colorado Springs, CO and Aurora, IL

The purpose of the investigation was to determine the root cause(s) as to why 79 of 250 hopper railcar bolsters had developed either vertical cracks, horizontal cracks, or both in bolsters after two years of service. The cracks were visually detected when mechanics were performing routine maintenance/repairs on a railcar.

The analysis started is a straightforward, simple manner - visual inspection. Each bolster in the train set was visually examined to determine whether cracks existed in the support webs of the bolster. A bolster is a truss-like structure in the truck assembly, which supports the car and transfers the weight to the wheel set. After visual indications were observed, representative bolsters/rail cars were selected for further examination.

The selected rail cars were disassembled so that the $2,200 \mathrm{lb}$ bolsters could be radiographed. X-rays confirmed the presence of horizontal and vertical cracks in the support webs of the bolsters. The radiographs show indications of porosity and lack of fusion at the mold parting lines. The bolsters were subsequently cut with a plasma-arc so that smaller sections could be sent to the laboratory for metallography.

Metallographic pieces were sectioned from the bolsters. Samples were ground and polished, and then micro etched using 10\% nitol. Photographs were taken prior to etching, showing the pockets of sand solidified within the pieces. Examination of the bolsters showed extensive improper weld repairs and lack of post weld heat treatment on the surface of the internal support webs. Further examination showed large amounts of sand under the surface of the metal. The sand was eroded from the mold during the casting process and was entrapped at or under the surface. In multiple instances, the defect (sand) was not completely removed (ground out) before weld repairs were placed over the top, a direct violation of specifications set forth by the governing body. The appearance of microstructure shows that insufficient, if any post-weld heat-treatment was performed.

The paper discusses the various techniques utilized both in the field and laboratory in order to detect, sort and analyze defects. Photographs, x-rays, micrographs, and fractographs serve as permanent record of the defects found in the product. The detailed analysis will be presented.
A. Contact radiograph -vertical shrinkage porosity and associated cracking;
B. Major crack, fatigue in bolster web, 23X;
C. Macro-etch cross section of improper weld repair, two cracks: under bead and in HAZ, 2.2X;
D. Weld after improper grinding. Sand deposit under bead instigated fatigue cracks, $3 X$;
E. SEM of shrinkage cracks typical voids, 30X;
F. Micro-porosity, shrinkage, $300 \mathrm{X}$. 


\section{A}
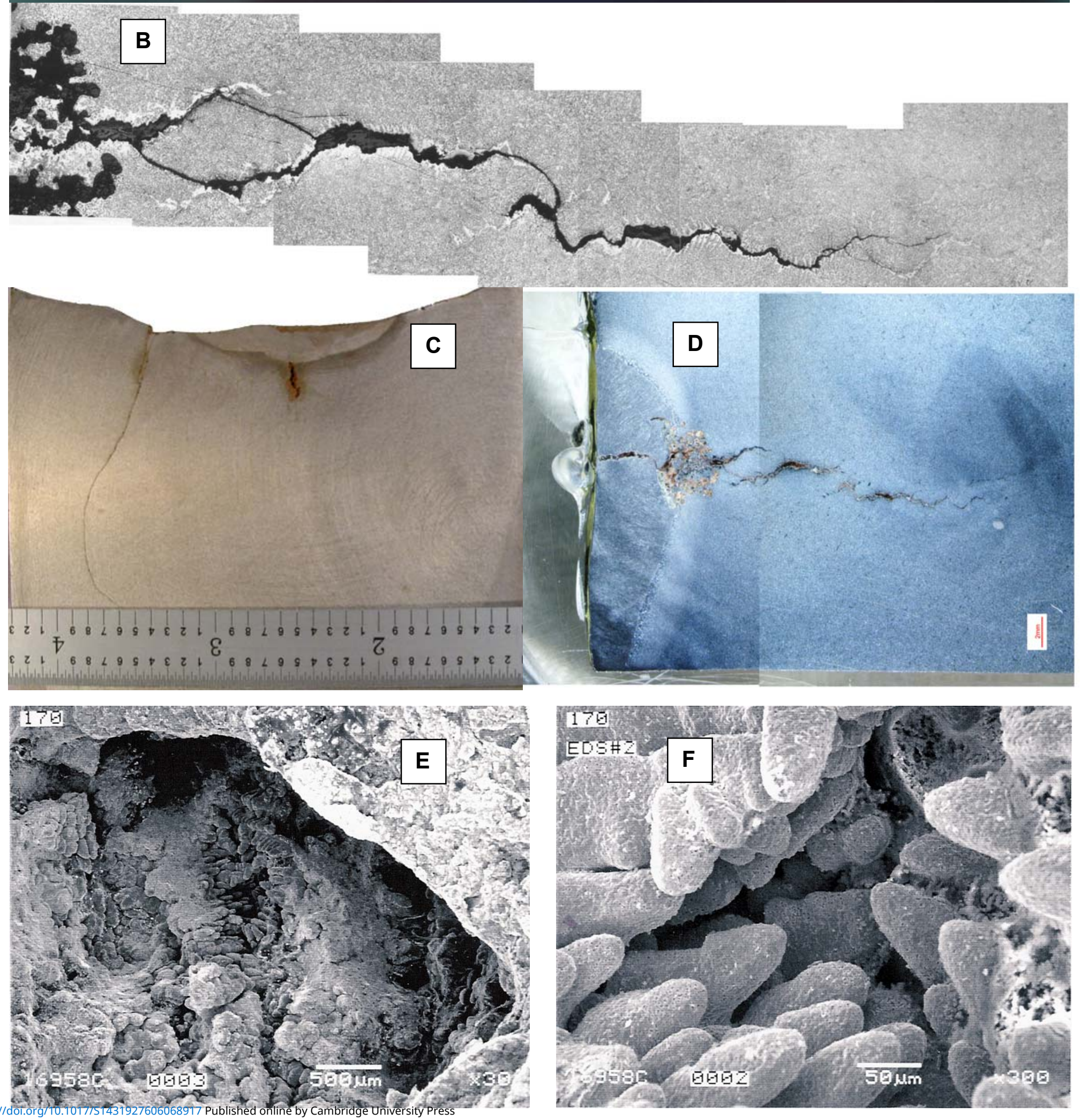